\title{
Photoreceptor Ablation Initiates the Immediate Loss of Glutamate Receptors in Postsynaptic Bipolar Cells in Retina
}

\author{
Felice A. Dunn \\ Department of Ophthalmology, University of California, San Francisco, San Francisco, California 94143
}

\begin{abstract}
Structural changes underlying neurodegenerative diseases include dismantling of synapses, degradation of circuitry, and even massive rewiring. Our limited understanding of synapse dismantling stems from the inability to control the timing and extent of cell death. In this study, selective ablation of cone photoreceptors in live mouse retina and tracking of postsynaptic partners at the cone-to-ON cone bipolar cell synapse reveals that early reaction to cone loss involves rapid and local changes in postsynaptic glutamate receptor distribution. Glutamate receptors disappear with a time constant of $2 \mathrm{~h}$. Furthermore, binding of glutamate receptors by agonists and antagonists is insufficient to rescue glutamate receptor loss, suggesting that receptor allocation depends on the physical presence of cones. These findings demonstrate that the initial step in synapse disassembly involves postsynaptic receptor loss rather than dendritic retraction, providing insight into the early stages of neurodegenerative disease.
\end{abstract}

Key words: glutamate receptor; neurodegenerative disease; retina; synapse; synapse disassembly; vision

\section{Introduction}

Diseases that disrupt cognitive function, sensory modalities, and muscular control commonly involve the disassembly of synapses within our nervous system. The majority of knowledge about the process of synapse disassembly comes from studies at the neuromuscular junction, where presynaptic and postsynaptic partners and associated proteins have been measured following motoneuron damage (Culican et al., 1998; Akaaboune et al., 1999; Pun et al., 2002; Walsh and Lichtman, 2003). Far less is known about CNS disorders. Lack of knowledge about the identity of involved neural circuits and cell types, as well as the sequence of disruption, has prevented a thorough understanding of disassembly in the CNS.

The retina provides a well characterized circuit in the CNS for studying the events of synapse disassembly. Extensive morphological and physiological definitions of cell types, ordered lamination of short-range dendrites and axons, identified presynaptic and postsynaptic partners, and logical mappings between spatial locations of cells and the visual field all contribute to why the

\footnotetext{
Received 0ct. 16, 2014; revised Dec. 1, 2014; accepted Dec. 21, 2014

Author contributions: F.A.D. designed research; F.A.D. performed research; F.A.D. contributed unpublished reagents/analytic tools; F.A.D. analyzed data; F.A.D. wrote the paper.

This work was supported through Grants EY-022910 (F.A.D.), Helen Hay Whitney Fellowship (F.A.D.), Karl Kirchgessner Foundation Vision Research (F.A.D.), and EY-017101 (Rachel 0. L. Wong). I thank Mei Zhang, John Campbell, and Jonathan Linton (Vision Core EY-001730) for care and genotyping of mice; Shellee Cunnington for technical assistance; Luca Della Santina for advice on statistical analysis; Thomas Hughes for the hLMcone-GFP mouse; Cheryl Craft for cone arrestin antibody; Catherine Morgans for mGluR6 antibody; Adam Bleckert, Florence D'Orazi, Clare Gamlin, Mrinalini Hoon, David Kastner, Philip Mardoum, Haruhisa Okawa, Sachihiro Suzuki, and Takeshi Yoshimatsu for helpful discussions; Greg Field, Alexander Sher, Jane Sullivan, and Huat Chye Lim for thoughtful comments on the manuscript; and Rachel 0. L. Wong and Fred Rieke (Howard Hughes Medical Institute) for supporting this work.

The authors declare no competing financial interests.

Correspondence should be addressed to Felice A. Dunn, Department of Ophthalmology, University of California, San Francisco, 10 Koret Way, Box 0730, San Francisco, CA 94143. E-mail: dunnf@vision.ucsf.edu.

DOI:10.1523/JNEUROSCI.4284-14.2015

Copyright $\odot 2015$ the authors $\quad 0270-6474 / 15 / 352423-09 \$ 15.00 / 0$
}

retina may be considered arguably one of the best understood circuits of the CNS (Masland, 2012). This retinal circuit is also subject to many debilitating diseases, several of which are associated with presynaptic damage. Retinal diseases such as rod and cone dystrophies and retinitis pigmentosa involve photoreceptor degeneration in the early stages (Al-Shamekh and Goldberg, 2014), which is then followed by massive rearrangement of the rest of the retinal circuitry long after the initial insult has occurred (Marc et al., 2003). The first step to understanding the sequence of events leading to complete disorganization is to study how the secondary neurons in the retina, the bipolar cells, react immediately after damage to photoreceptors. This fundamental piece of knowledge remains hidden because a temporally and spatially controlled model for photoreceptor damage has not been previously used.

Here, a well defined connection in the mouse retina between cone photoreceptors and a specific type of ON cone bipolar cell allowed for the visualization and reconstruction of presynaptic and postsynaptic partners, as well as the localization of postsynaptic receptors. Each of these type $6 \mathrm{ON}$ cone bipolar cells receives input from a stereotyped number of cones (Wässle et al., 2009; Dunn and Wong, 2012). At this synapse between a specific type of bipolar cell and all its presynaptic cone partners, live-cell imaging, targeted ablation of presynaptic cones, immunostaining for postsynaptic receptors, and fixed-tissue imaging of the same cell were accomplished to examine the effects of ablating presynaptic partners that provide input to an identified cone bipolar cell within a day following damage. Findings indicate that the immediate reaction to photoreceptor damage involves metabotropic glutamate receptor loss rather than major changes in bipolar cell dendritic morphology that are prominent at later stages of retinal damage (Strettoi et al., 2003). Furthermore, these changes in glutamate receptor allocation are localized to specific cone inputs and occur within $2 \mathrm{~h}$ following ablation of a presynaptic cone. 

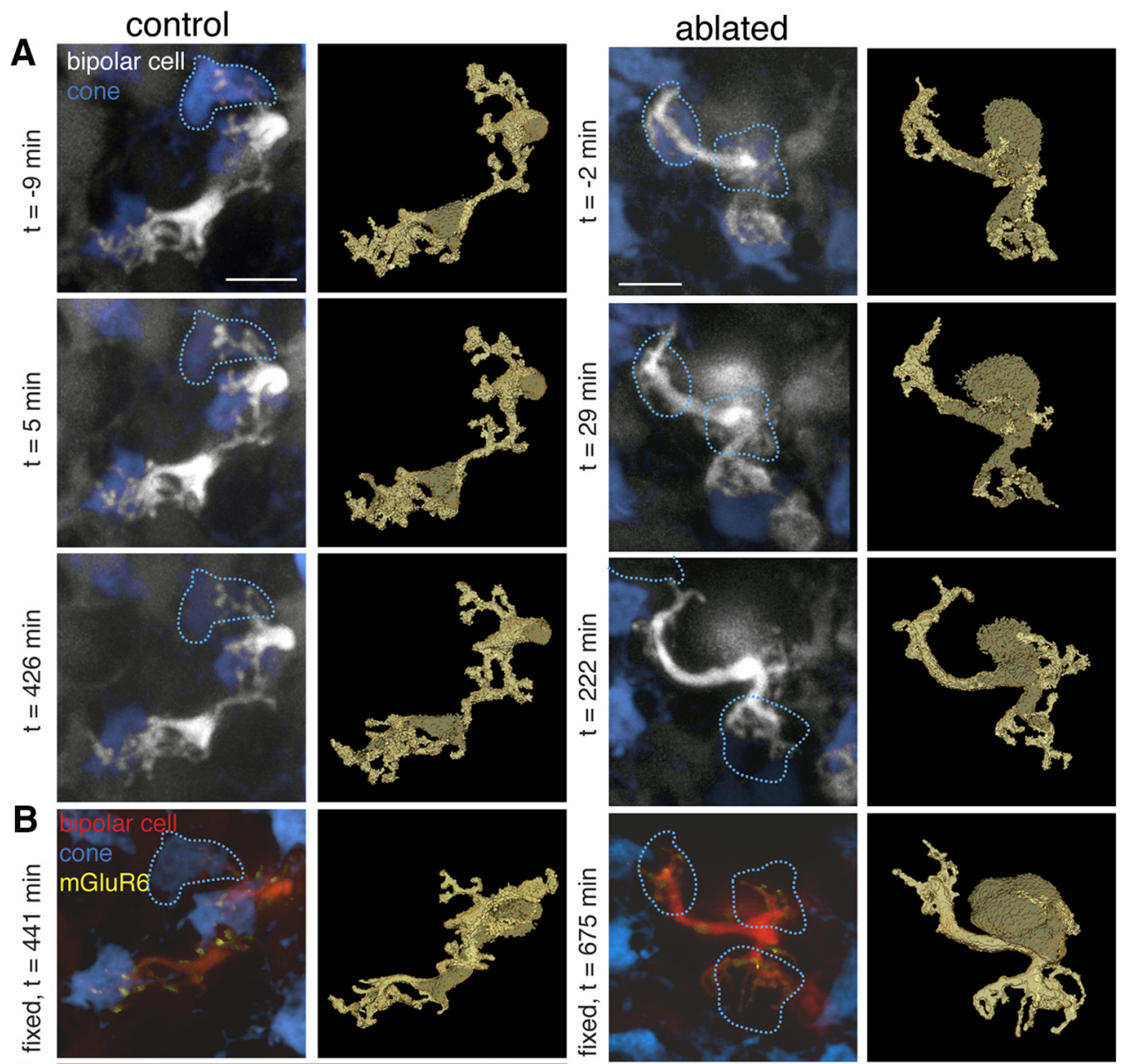

C
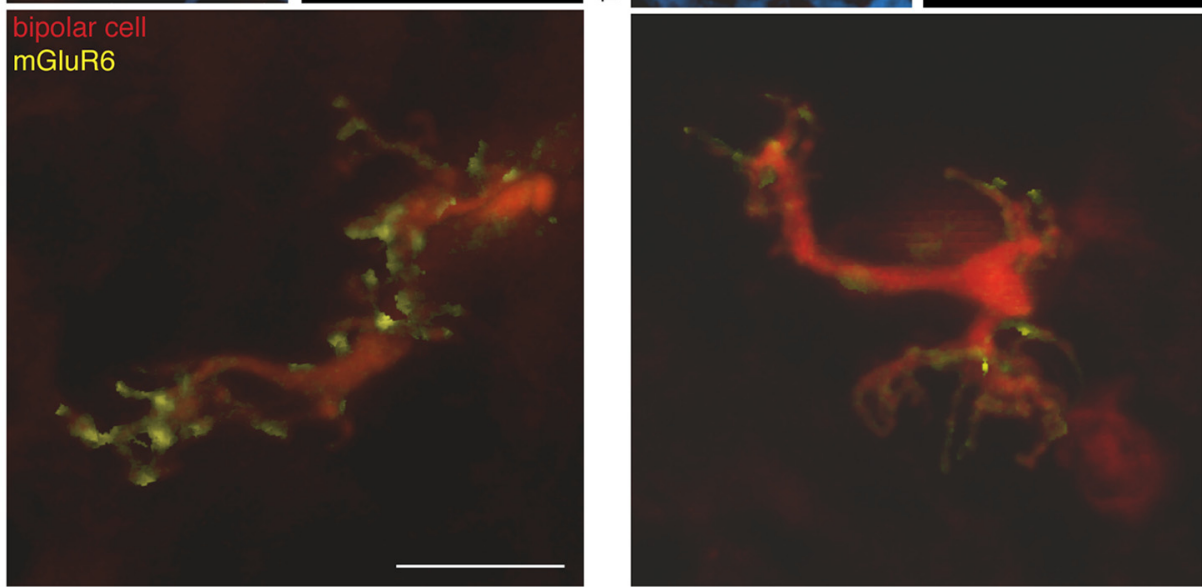

Figure 1. Major changes to glutamate receptors in bipolar cell dendrites within $24 \mathrm{~h}$ after ablation of presynaptic cones. $A$, Two-photon images of live retina from $h L M$-GFP $\times m G / u R 6-T d T o m a t o$ transgenic mice where cones containing M opsin (blue) and a sparse subset of $0 \mathrm{~N}$ bipolar cells (gray) express fluorescent proteins. Left two columns, Type $60 \mathrm{~N}$ cone bipolar cell in which the top cone input was bleached at time $(t)=0$, but was not ablated with the two-photon laser (dotted lines). Right two columns, Type $60 \mathrm{~N}$ cone bipolar cell in which all three cone inputs were ablated (dotted lines, two cones ablated at $t \sim 0$, third cone ablated at $t \sim 222 \mathrm{~min}$ ). Right panels, Label field of the bipolar dendrites during the time lapse. $\boldsymbol{B}$, Confocal images of the same two bipolar cells after fixation and immunostaining for cone arrestin (blue) and the postsynaptic glutamate receptor mGluR6 (yellow). Left, The bleached cone is revealed by cone arrestin immunostaining. Each of the dendritic tips contains mGluR6 puncta associated with cone inputs. Right, The ablated cones are missing from the cone arrestin immunostaining. $C$, Close-up view of bipolar dendrites and the mGluR6 associated with the dendrites. Scale bars, $5 \mu \mathrm{m}$.

These results demonstrate that metabotropic glutamate receptors in the retina are susceptible to presynaptic damage, regulated locally at each presynaptic input, and an integral player in the first response to photoreceptor damage.

\section{Materials and Methods}

Animals and tissue preparation. All procedures were performed in accordance with the University of Washington Institutional Animal Care and
Use Committee protocols. Male and female mice over the age of postnatal day 21 were killed with $5 \%$ isoflurane overdose and by cervical dislocation. To examine the reaction of individual bipolar cells following damage to photoreceptors, we used the $h L M-G F P$ mouse line, in which cones containing M opsin express GFP (Fei and Hughes, 2001), crossed to the Grm6-tdTomato line, in which a sparse population of ON bipolar cells expresses tdTomato (Kerschensteiner et al., 2009). Retinae were isolated from the sclera and pigment epithelium, and three to four reliev- 


\begin{tabular}{lrll}
$\begin{array}{l}\text { Table 1. Ratio of dendritic to somatic mGluR6 intensities across conditions and } \\
\text { results from two-sample } t \text { test }\end{array}$ & \\
\hline $\begin{array}{l}\text { Condition: control or ablated } \\
\text { cone or bipolar cell }\end{array}$ & $\begin{array}{l}\text { Ratio of dendritic to somatic } \\
\text { mGluR6 intensities } \\
\text { (mean } \pm \text { SEM) }\end{array}$ & $\begin{array}{l}\text { Results from } \\
\text { two-sample } t \text { test }\end{array}$ \\
\hline $\begin{array}{l}\text { Ames solution } \\
\quad \text { Control }\end{array}$ & 67 & $1.74 \pm 0.06$ & $h=1, p=7 \mathrm{e}-17$ \\
$\quad$ Ablated & 46 & $0.97 \pm 0.04$ & \\
LY/APB & & & \\
$\quad$ During: control & 25 & $1.46 \pm 0.06$ & $h=1, p=3.48 \mathrm{e}-5$ \\
$\quad$ During: ablated & 5 & $0.79 \pm 0.04$ & \\
$\quad$ After: control & 7 & $2.83 \pm 0.79$ & \\
$\quad$ After: ablated & 2 & $1.13 \pm 0.01$ & \\
APB & & & \\
$\quad$ During: control & 10 & $1.46 \pm 0.07$ & \\
$\quad$ During: ablated & 7 & $0.91 \pm 0.04$ & \\
$\quad$ After: control & 10 & $1.67 \pm 0.11$ & \\
$\quad$ After: ablated & 7 & $1.05 \pm 0.06$ & \\
LY & & & \\
$\quad$ During: control & 16 & $2.39 \pm 0.20$ & \\
$\quad$ During: ablated & 3 & $1.23 \pm 0.41$ & \\
Ames solution: neighbor & 11 & $1.57 \pm 0.08$ & \\
$\quad$ bipolar cell ablation & & & \\
\hline
\end{tabular}

Solution conditions and control or ablated cells in the first column. Only the cones that were ablated with an interval of $>120$ min between ablation and fixation were included in the ablated cone population. The extreme right column shows the results of the two-sample $t$ test for the pairwise comparison between the control and ablated cones in a given solution condition. $h=0$ indicates that the null hypothesis could not be rejected with probability $p$; $h=1$ indicates that the null hypothesis could be rejected with probability $p ; \mathrm{LY}, \mathrm{LY}-341495 ; \mathrm{APB}, \mathrm{L}-\mathrm{APB}$.

ing cuts were made to mount the retina flat on a nitrocellullose membrane (Millipore). The retina was secured in a custom-made chamber with a platinum ring resting on the edges of the filter paper. The retina was perfused with bicarbonate-buffered Ames solution saturated with $95 \%$ oxygen and $5 \%$ carbon dioxide at $32-35^{\circ} \mathrm{C}$. The flow rate of solution was maintained at $3 \mathrm{~mL} / \mathrm{min}$.

Live retina imaging and ablation. Cones and bipolar cells were imaged with a two-photon microscope with a $60 \times, 1.1$ numerical aperture (NA) objective (Olympus) over 1-24 h while the retina was kept alive. Imaging was done with the Ti-sapphire laser (Spectra-Physics) at $910 \mathrm{~nm}$ with preobjective power of 5-20 mW. Voxel sizes were $0.046-0.058 \mu \mathrm{m}(x-$ axis, $y$-axis) and $0.3 \mu \mathrm{m}$ ( $z$-axis). Each plane was averaged three to four times (using a Kalman filter).

Individual cones or bipolar cells were ablated by restricted scanning at $775 \mathrm{~nm}$ with preobjective power of $100-400 \mathrm{~mW}$. For cone ablations, the laser was restricted to the axon stalk of the cone. For bipolar cell ablations, the laser was restricted to a $16 \times 16$ pixel region at a $10 \times$ zoom within the cell body. The laser was scanned for $<10$ s until a sudden increase in fluorescence indicated the death of the cell. If this fluorescence increase was not detected within $10 \mathrm{~s}$, a rest interval of $30 \mathrm{~s}$ prevented overheating that region of tissue, then the restricted laser scanning was attempted again after the laser power was increased by $50 \mathrm{~mW}$. Only in cases where the sudden increase in fluorescence was observed was the cone considered ablated. These cases matched the absence of cone arrestin in the subsequent immunostaining (Fig. $1 A$, right). Otherwise, when the laser bleached the fluorescence rather than ablated the cone, the cone would be revealed by the cone arrestin antibody after fixation (Fig. 1A, left).

Bipolar dendrites were imaged at varying intervals after cones were ablated. The location of each bipolar cell was mapped onto a drawing of the retina. Fiducial markers such as neighboring individual and clusters of fluorescent cells, borders of the retina, and relieving cuts were used to identify locations so that the same cell could be imaged repeatedly. Between 1 and 17 individual bipolar cells were imaged in each retina.

Pharmacology. Pharmacological agents were added to the solution in which the retina was perfused during live imaging. For the combination of metabotropic glutamate receptor 6 (mGluR6) agonists and antagonists in Figure 5, $5 \mu \mathrm{M} \mathrm{L}$-APB (Tocris Bioscience) and $7.5 \mu \mathrm{M} \mathrm{LY}-341495$ (Tocris Bioscience) were added to the Ames solution. For the mGluR6 agonist alone, $10 \mu \mathrm{M}$ L-APB was used. For the mGluR6 antagonist alone,
$10 \mu \mathrm{M}$ LY-341495 was used. The entire retina was constantly perfused with these pharmacological reagents either during and after cone ablation or only after cone ablation. The pharmacological reagents were perfused across the retina for the remaining time until fixation.

Immunostaining and fixed retina imaging. After the live-imaging experiment, the retina was fixed in 4\% paraformaldehyde in ACSF for 15 min. For immunostaining, retinae were incubated in blocking solution ( $5 \%$ normal donkey serum and $0.5 \%$ Triton $\mathrm{X}-100$ ) for $1 \mathrm{~d}$, in primary antibodies for $5 \mathrm{~d}$, and in secondary antibodies for $1 \mathrm{~d}$ at $4^{\circ} \mathrm{C}$. Primary antibodies against cone arrestin (1:500; Nikonov et al., 2008; a gift from Cheryl Craft, University of Southern California, Los Angeles, CA) and mGluR6 (1:200; Morgans et al., 2006; Catherine Morgans, Oregon Health \& Science University, Portland, OR) were used to label presynaptic cones and postsynaptic glutamate receptors. The following secondary antibodies were used: 1:500 donkey anti-sheep 633 (Invitrogen) and donkey anti-rabbit Alexa Fluor 488 or Dylight 488 (The Jackson Laboratory). The retinae were mounted in Vectashield (Vector Laboratories) underneath a coverslip. Bipolar cells previously imaged were identified using maps drawn during the live-imaging experiment. Bipolar cells were imaged using a confocal microscope (FV-1000, Olympus) with a $60 \times$ objective, 1.35 NA. Voxel sizes were $0.066-0.069 \mu \mathrm{m}$ ( $x$-axis, $y$-axis) and $0.2 \mu \mathrm{m}$ ( $z$-axis).

Image analysis. Each three-dimensional image stack was median filtered by 3 pixels and normalized into an 8-bit image before analysis. In Amira (Mercury Computer Systems), the dendrites and soma of the bipolar cell were masked and used to extract the mGluR6 signal within the bipolar cell of interest. The maximum intensity projection of the mGluR6 signal was used to find the average intensity in either the dendritic or somatic region. In MetaMorph (Universal Imaging), the outline of the dendrites that fell within the region of either an existing cone (control) or an ablated cone was traced. The average intensity of this region was taken as the dendritic mGluR6 average. The average mGluR6 intensity in the dendrites was compared with the average intensity of the somatic region for each cell. In some instances, a dendritic branch fell within the somatic region in the maximum intensity projection. In these cases, an outline was drawn to encompass the soma and avoid this dendritic branch.

Statistical analysis. A two-sample $t$ test was used to test for differences between the ratios of dendritic to somatic mGluR6 intensities for bipolar cell dendrites opposite control and ablated cones. Results from each pairwise comparison within a drug condition is displayed in Table 1. Data in Figure $3 E$ were fit to a straight line and inversely weighted by the SEM of each point. Average data in Figures $4 E, 5 E$, and $6 D$ were fit by a single exponential and were inversely weighted by the SEM of each point. To test for differences across Ames solution and pharmacological manipulations, a one-way ANOVA was run across control cones and also across ablated cones (see Figs. 5, 6, statistical results). To test for differences between control cones and ablated bipolar cells, a one-way ANOVA was run (see Fig. 7, for statistical results).

\section{Results}

Presynaptic cone ablation has minimal short-term effects on the dendritic morphology of postsynaptic cone bipolar cells and major effects on dendritic glutamate receptors

To examine the immediate effects of presynaptic photoreceptor ablation on postsynaptic neurons in adult animals ( $>$ postnatal day 21), live retinae from the $h$ LMcone-GFP $\times$ Grm6-TdTomato transgenic mouse line were imaged with a two-photon laser. In these retinae, cones with middle wavelength-sensitive opsin express GFP (Fei and Hughes, 2001) and a subset of ON bipolar cells express TdTomato (Kerschensteiner et al., 2009). Individual type $6 \mathrm{ON}$ cone bipolar cells and a subset of their presynaptic cone partners could be imaged repeatedly in a time lapse (Fig. $1 A$ ). The two-photon laser was focused on the axon stalk of individual cones to either bleach the cone (Fig. $1 \mathrm{~A}$, left) or generate enough focal heat to ablate the cone (Fig. $1 A$, right). After fixation and immunostaining for the full complement of cones with an 


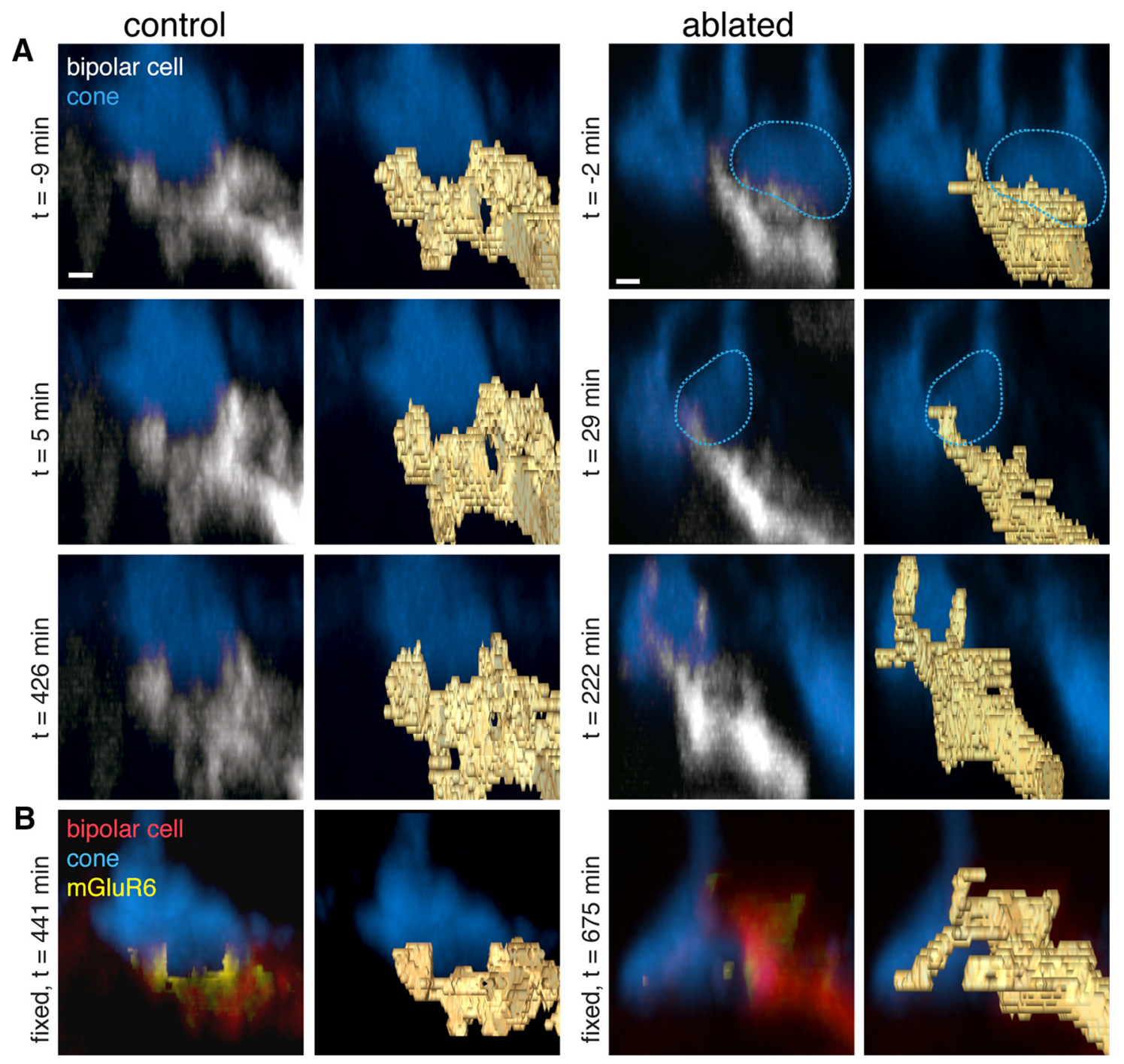

Figure 2. Minor changes in the bipolar cell dendritic tips after loss of a presynaptic cone. A, Side views of dendritic branches and single cone contact from the same cells as in Figure 1. Bottom cone contact from left bipolar cell and top cone from right bipolar cell. Images taken with the two-photon laser during live imaging. Left, Bipolar cell dendritic tips when the cone has not been perturbed. Right, Bipolar cell dendritic tips when a presynaptic cone has been ablated by the two-photon laser at time $(t)=0$. Dotted line outlines the cones that were ablated. Right panels, Labeled field of the bipolar dendritic branches. $\boldsymbol{B}$, Confocal images of the same dendritic branches after fixation and immunostaining for cone arrestin (blue) and the postsynaptic glutamate receptor mGluR6 (yellow). Scale bars, $1 \mu \mathrm{m}$.

antibody against cone arrestin (Nikonov et al., 2008; Fig. 1B), the same cells from the live-imaging experiment were located. Cones that were bleached during the live-cell imaging became visible with the cone arrestin (Fig. 1B, left), while cones that were ablated continued to be absent from the cone arrestin staining (Fig. $1 B$, right).

The following two aspects of the reaction of a postsynaptic bipolar cell to the loss of their presynaptic partners were examined: dendritic morphology and glutamate receptor staining. $\mathrm{Bi}$ nary masks were drawn around the bipolar cell dendrites (Fig. 1A, gold outlines). Branching changed in the bipolar cell, which lost all of its presynaptic inputs, but the alterations were minor, even in the vertical plane of the three-dimensional image stack (Fig. 2). The more obvious reaction to the loss of presynaptic inputs was the elimination of postsynaptic glutamate receptors (Fig. 1C). Under control conditions, immunostaining for the mGluR6 found in the type $6 \mathrm{ON}$ cone bipolar cells presents as dense clusters of mGluR6s in the dendritic claws that contact each cone terminal. mGluR6 immunoreactivity and clustering were decreased in the dendritic tips of the bipolar cells without cone inputs (Fig. $1 B, C$ ).
Stability of postsynaptic glutamate receptors are independently regulated at sites of cone contact

To further explore the loss of glutamate receptors from the postsynaptic bipolar cell dendrites, a subset of cone inputs was ablated. Each type $6 \mathrm{ON}$ cone bipolar cell receives input from two to five cones, and the mGluR6 associated with each cone tends to be clustered densely and locally (Dunn and Wong, 2012). Thus, the following experiments tested whether mGluR6s at these individual contact sites are independently regulated. Instead of ablating all the cone inputs to an individual bipolar cell, a subset of cone inputs were ablated in live retina (Fig. $3 A, B$ ). Following fixation and immunostaining for the remaining cones and mGluR6s, mGluR6s disappeared only from the dendrites that once contacted an ablated cone. The mGluR6s opposite to intact cones remained properly allocated (Fig. $3 C$ ). Figure $3 C$ (bottom) plots the average mGluR6 signal in the bipolar cell dendritic region that once contacted ablated or surviving cones versus the average mGluR6 signal in the bipolar cell soma. Bipolar cell dendritic tips that once contacted ablated cones had intensity ratio values that fell on or below the line of slope unity, whereas bipolar cell den- 

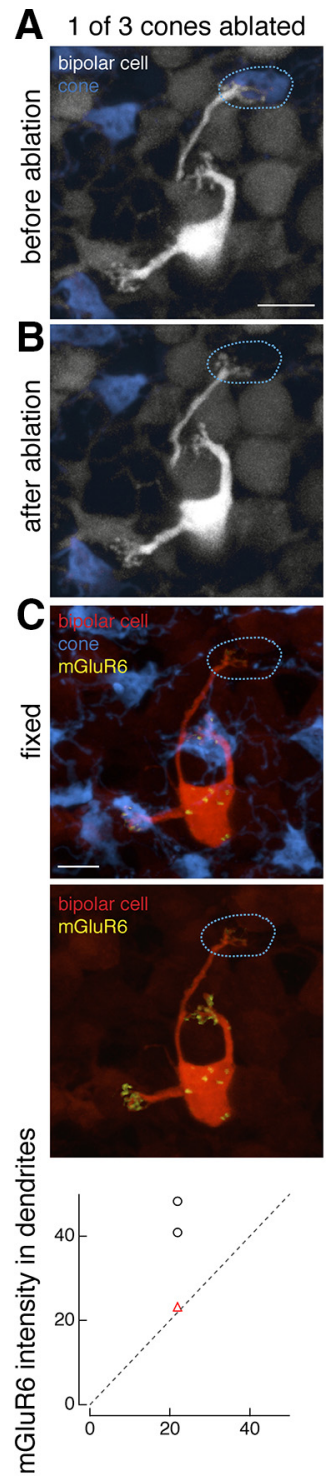
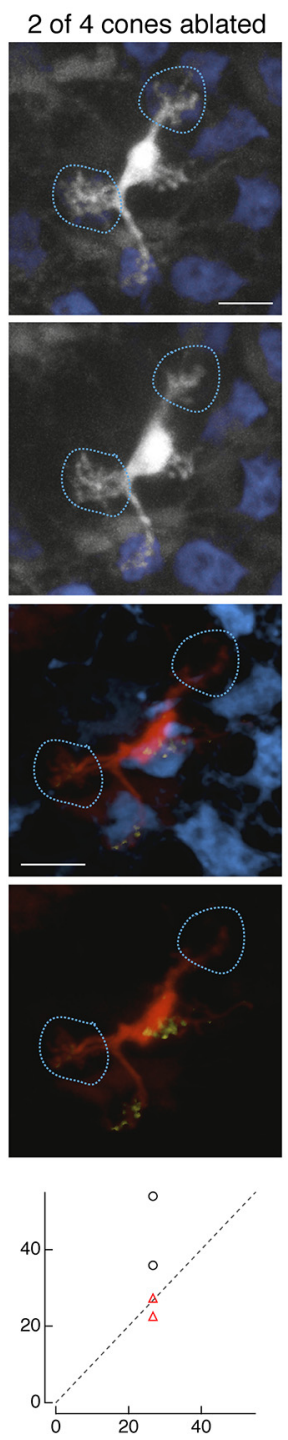

mGluR6 intensity in soma
3 of 5 cones ablated
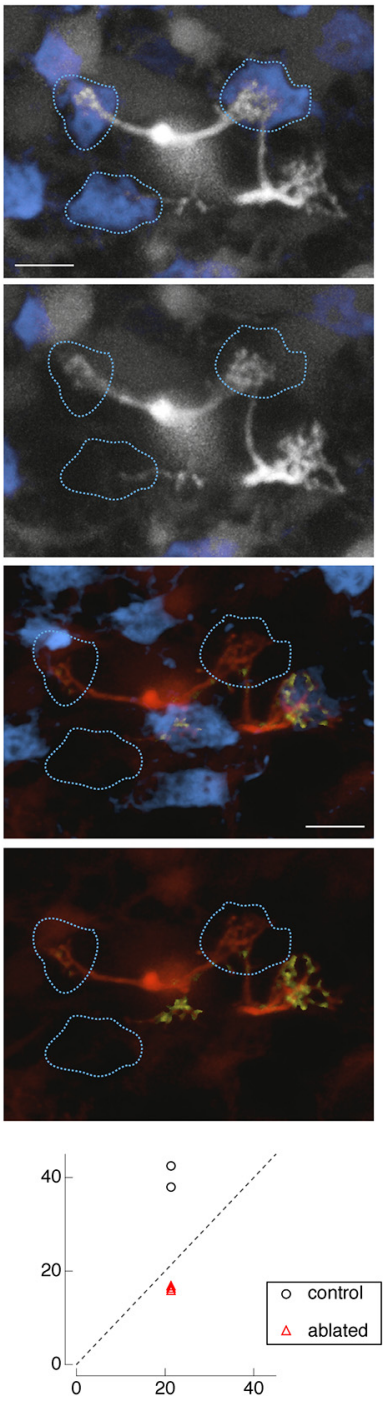

D
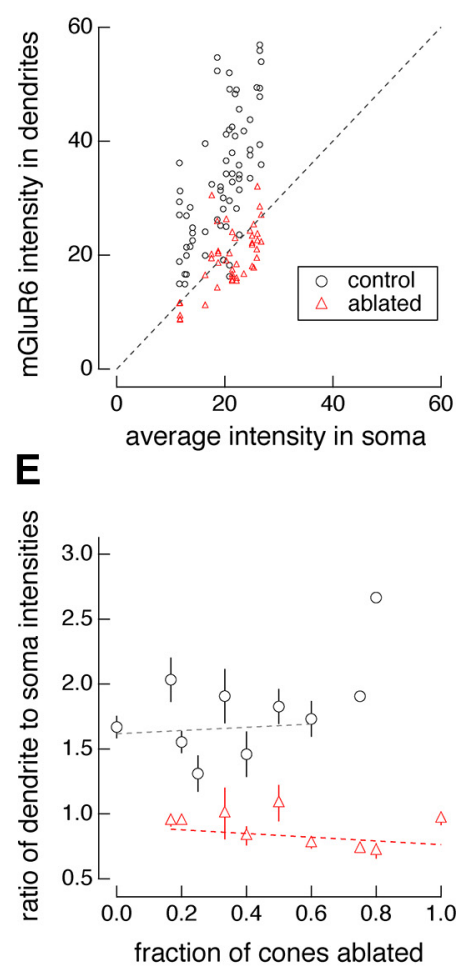

Figure 3. Postsynaptic glutamate receptors are independently regulated at sites of cone contact. $\boldsymbol{A}, \boldsymbol{B}$, Two-photon images of live retina before $(\boldsymbol{A})$ and after $(\boldsymbol{B})$ cone ablation. $\boldsymbol{C}$, Confocal images of fixed retina. Examples of type $60 \mathrm{~N}$ cone bipolar cells in which increasing fractions of cone inputs have been ablated: one of three cones (left), two of four cones (middle), and three of five cones (right). Locations of ablated cones are indicated by dotted lines. Retinae were fixed at the following times after cone ablation: $164 \mathrm{~min}$ (left), 675 min (middle), and 705 min (right). Graphs underneath show the quantification of average dendritic tip mGluR6 immunostaining intensity versus average somatic mGluR6 immunostaining intensity in regions where cones remain intact (black circles) and where cones have been ablated (red triangles) for each individual bipolar cell shown in the time lapse above. $D$, Quantification of average intensities of $\mathrm{mGluR6}$ immunostaining in dendritic to somatic regions across the entire population of bipolar cells examined where cones remain intact (black circles) or have been ablated (red triangles). Two-sample $t$ test between the ratio of dendritic to somatic mGluR6 immunostaining average intensities compared with control cones $(n=67)$ and ablated cones $(n=46)$ reveals that the null hypothesis can be rejected at $p<$ 7e-17.E, Ratio of average dendritic to somatic intensities of mGluR6 immunostaining as a function of the fraction of cones that were ablated for each type $60 \mathrm{~N}$ cone bipolar cell. Data points represent the mean \pm SEM. Data points fit with a line $(y=a+b x)$ with the following coefficients and $95 \%$ confidence intervals: $a=1.6 \pm 0.2, b=0.13 \pm 0.6$ (control) and $a=0.91 \pm 0.1, b=-0.14 \pm$ 0.2 (ablated). Data in $\boldsymbol{D}$ and $\boldsymbol{E}$ include bipolar cells for which the interval between cone ablations and fixation was $>2 \mathrm{~h}$. Scale bars, $5 \mu \mathrm{m}$.

dritic tips that contacted control cones fell above the line of slope unity. An intensity ratio of 1 indicates that the mGluR6 intensity level at the dendritic tips is equivalent to the background mGluR6 intensity level at the soma, where mGluR6 is not normally found. In other words, the clustering of mGluR6s at the dendritic tips has been disrupted at sites where cones were ablated. Across the population of bipolar cells examined, this trend separated the mGluR6 intensities in the dendrites of ablated compared with unablated cones (Fig. 3D). All cells used in this quantification had an interval between ablation and fixation of $>2 \mathrm{~h}$. To determine whether the mGluR6 intensity reduction in the dendritic branches that lost their presynaptic partner depended on the fraction of cones that had been ablated from a bipolar cell, the mGluR6 intensity was plotted as a function of this fraction and no significant dependence was revealed, suggesting that mGluR6 at each of the cone contacts is independently regulated (Fig. 3E, statistics).

Postsynaptic glutamate receptors are lost with a time constant of $2 \mathrm{~h}$ following cone ablation

Next, to determine the time course at which the mGluR6 is eliminated from the bipolar cell dendritic tips following cone ablation, the interval between the time of cone ablation and fixation of the retina was varied (Fig. 4). When this interval was $50 \mathrm{~min}$, the mGluR6s remained within the dendritic tips of the bipolar cell (Fig. $4 A, B$ ). In a single bipolar cell, two cones were ablated at two time points. The bipolar cell dendritic branch underneath 
A
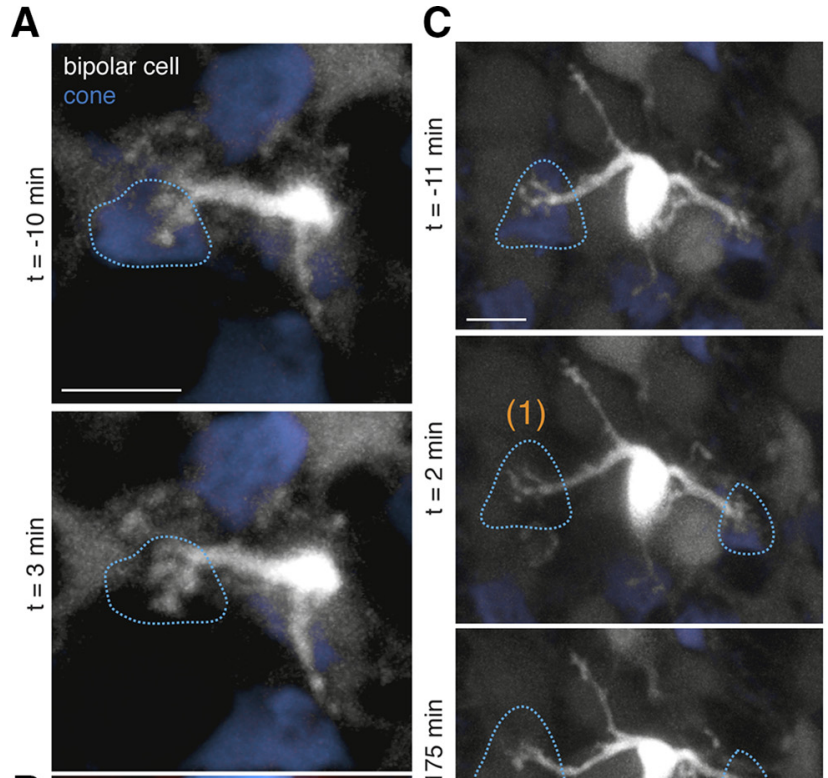

B
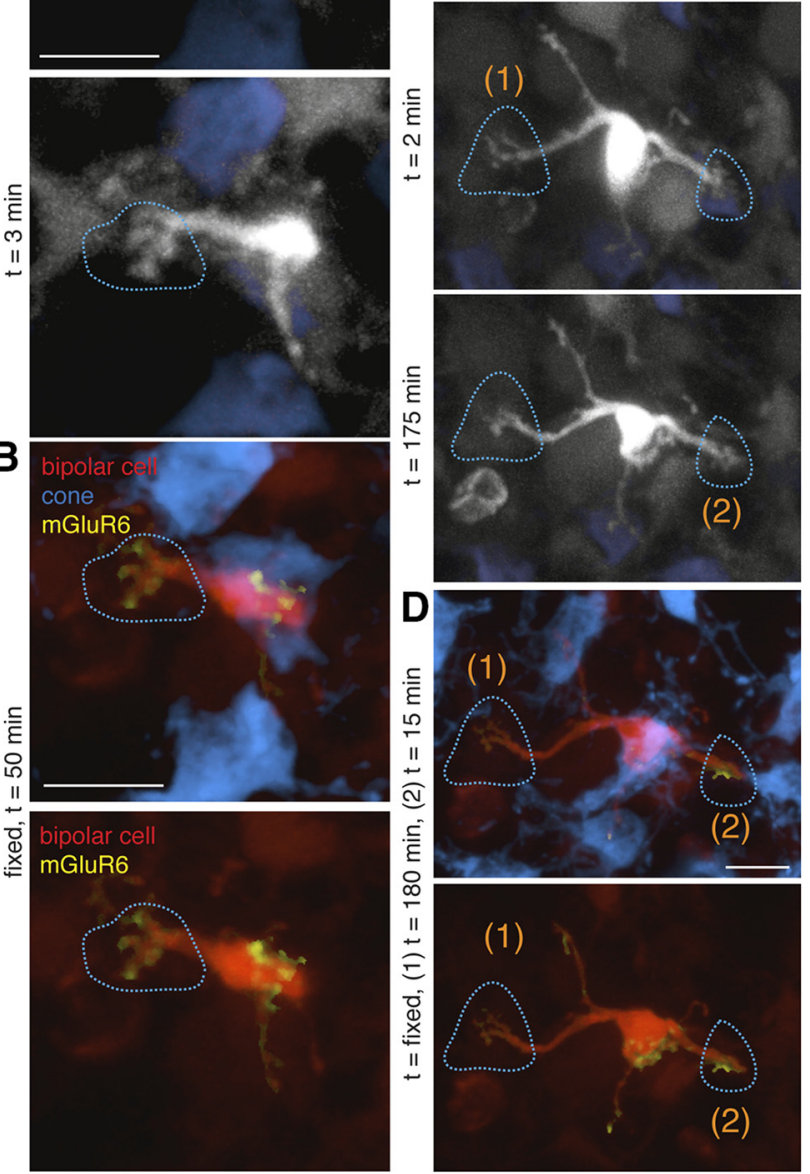

$\mathbf{E}$

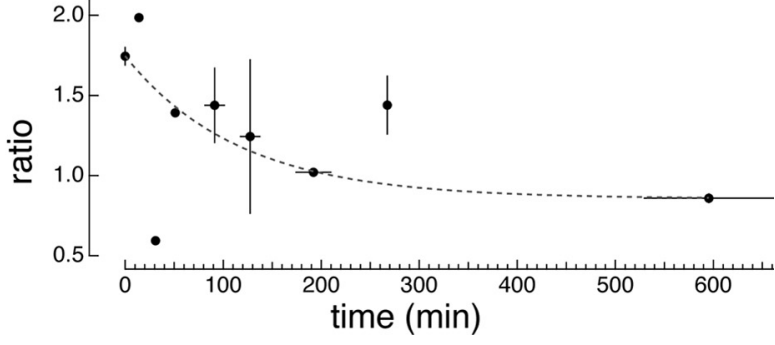

Figure 4. Time course of receptor loss: mGluR6 is lost with a time constant of $2 \mathrm{~h}$ following the ablation of presynaptic cones. $A, C$, Two-photon images of type $60 \mathrm{~N}$ cone bipolar cells in live retina. $\boldsymbol{B}, \boldsymbol{D}$, Confocal images of the same bipolar cells after fixation of the retina. $A$, Time lapse of a bipolar cell immediately before and after ablation of a single cone at time $=0 . \boldsymbol{B}$, Same bipolar cell in a retina fixed $50 \mathrm{~min}$ after the cone ablation. $\boldsymbol{C}$, Time lapse of a bipolar cell immediately before and after ablation of one cone (1) at time $(\mathrm{t})=0$ and then after ablation of a second cone (2) at time $=165 \mathrm{~min}$. $\boldsymbol{D}$, Same bipolar cell in the retina fixed $180 \mathrm{~min}$ after ablation of the first cone and $15 \mathrm{~min}$ after ablation of the second cone. Sites of ablated cones are indicated by dotted lines. $\boldsymbol{E}$, Average dendritic to somatic intensity ratios of mGluR6 immunostaining across the population of type $60 \mathrm{~N}$ cone bipolar cells as a function of the interval between ablation and fixation. Points represent the mean $\pm S E M$ for ratio and the mean \pm SD for time ( $n=120$ cone contacts). Points at time 0 represent the population of control cones. Data points fit with a single exponential $[y=y 0+A \exp (-1 / \tau x)]$ with the following coefficients: $y 0=0.86 \pm 0.03, A=0.89 \pm 0.07, \tau=116 \pm 0.07$. The time constant for receptor elimination $(\tau)$ is $116 \mathrm{~min}$. Scale bars, $5 \mu \mathrm{m}$. the cone that was ablated with a 15 min interval retained its mGluR6, whereas the branch underneath the cone that was ablated with a $180 \mathrm{~min}$ interval lost its mGluR6. These results suggest that mGluR6 is regulated independently within the same bipolar cell across different dendritic tips and that regulation of mGluR6 within this bipolar cell occurs between 50 and $180 \mathrm{~min}$. Across bipolar cells whose cone inputs had been ablated, the ratio of mGluR6 intensity in the dendritic tips compared with the cell soma as a function of time revealed that the steady-state ratio was reached by $200 \mathrm{~min}$. The ratio could be fit with a single exponential with a time constant of $116 \pm 0.07 \min (n=120$ cones; Fig. $4 E)$. Thus, the process of mGluR6 elimination occurs with a time constant of $\sim 2 \mathrm{~h}$ after ablation of a presynaptic partner-the earliest reported reaction to loss of presynaptic input.

Bound glutamate receptors cannot rescue the loss of mGluR6 The observation that mGluR6 disappearance occurs after a $2 \mathrm{~h}$ delay following cone ablation led to the question of whether binding of these receptors by agonists and antagonists could prevent their disappearance. To test this, concentrations of the mGluR6 agonist APB and antagonist LY-341495 were chosen to match the fraction of receptors occupied under normal dark conditions (Ala-Laurila et al., 2011). At these concentrations of agonists and antagonists, the ON bipolar cell-mediated b-wave of the electroretinogram was eliminated, indicating that all mGluR6s were bound and glutamate released by the photoreceptors could not be detected by the bipolar cells (Dunn et al., 2013). In other words, the ON bipolar cell light response was eliminated by the drug concentrations used here. The agonist/antagonist mixture was perfused either during and after the cone ablation (Fig. $5 A, B$, left column) or immediately after the cone was ablated (Fig. $5 A, B$, right column). Neither manipulation prevented the mGluR6 disappearance from the bipolar dendritic tips where presynaptic cones had been ablated, which is indicated by the separation of control versus ablated cone sites under the pharmacological manipulation (Table 1, results of two-sample $t$ tests; Fig. $5 C)$. With the agonist alone, in which all the mGluR6s should be bound and the transduction cascade activated, mGluR6s continued to disappear from the dendritic terminals of ablated sites (Fig. 5D). Likewise, the antagonist alone failed to rescue mGluR6 (Fig. 6). A cone was ablated from the bipolar cell dendritic tip during and after perfusion of the mGluR6 antagonist LY341495 (Fig. 6A,B). mGluR6s disappeared from the bipolar cell dendrites opposite to the ablated cones (Fig. $6 \mathrm{C}$ ) and was lost on a time course similar to that in the Ames solution condition (Fig. 6D).

For each of the control cones under Ames solution and mGluR6 agonist and/or antagonist, a one-way ANOVA revealed that the ratio of dendritic to somatic mGluR6 intensities was significantly different for mGluR6 agonist/antagonist and mGluR6 antagonist compared with Ames solution, but not for the mGluR6 agonist compared with Ames solution (Figs. 5, 6, statistics). Such results suggest that the antagonist increased the ratio of dendritic to somatic mGluR6 intensities in the bipolar cells (Table 1, mean ratios). However, for each of the ablated cones under Ames solution and mGluR6 agonist and/or antagonist, the one-way ANOVA revealed no significant differences among the Ames solution and all pharmacological conditions (Figs. 5, 6, statistics). Thus, the cone ablation uniformly caused the elimination of mGluR6 from the bipolar cell dendrites, independent of the differences in the mGluR6s at sites of control cones. 

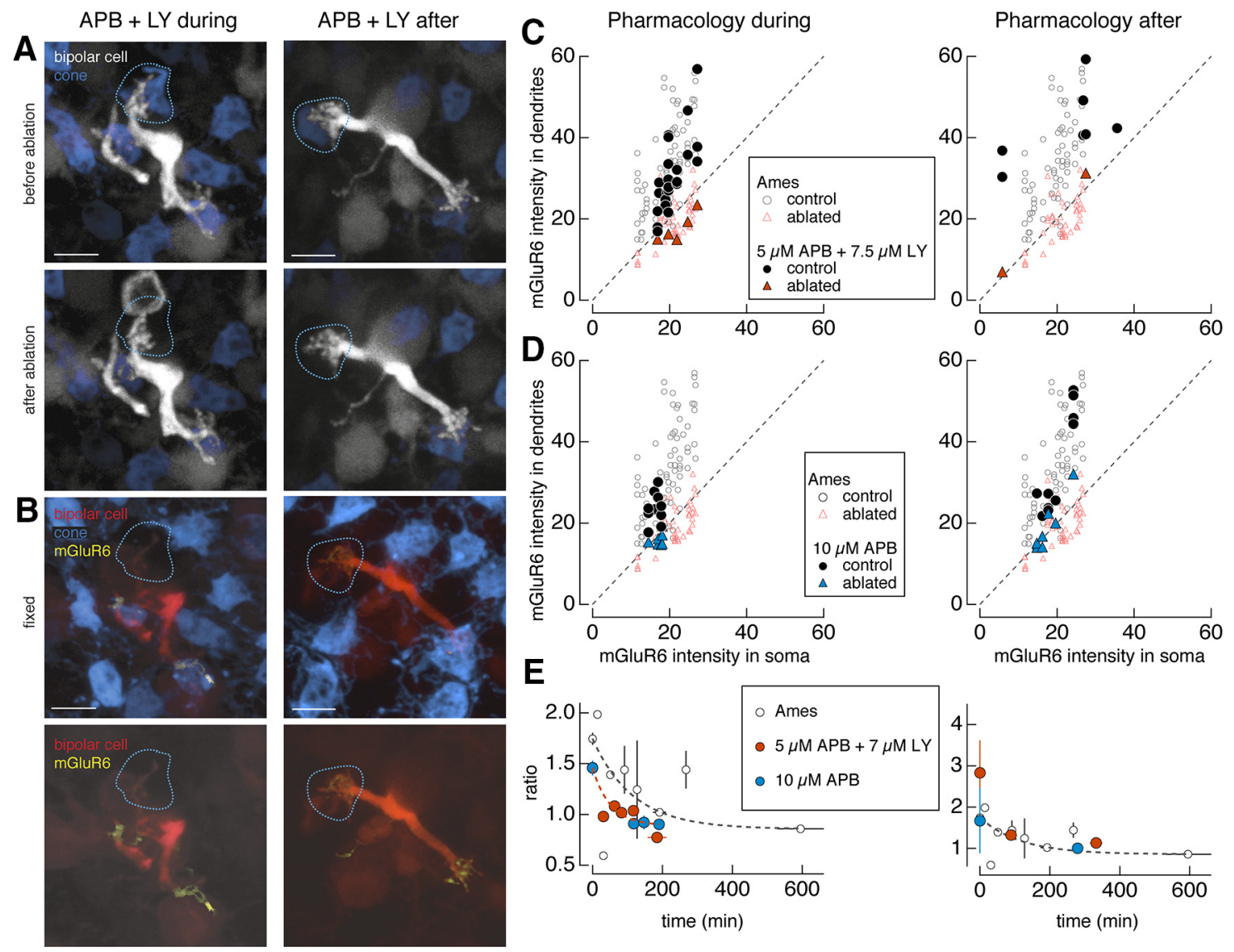

Figure 5. Pharmacological occupation of glutamate receptors is insufficient to rescue mGluR6. $A, B$, Two-photon images of type $60 \mathrm{~N}$ cone bipolar cells in live retina $(\boldsymbol{A})$ and confocal images of the same bipolar cells in fixed retina (B). $\boldsymbol{A}$, Type $60 \mathrm{~N}$ cone bipolar cells in which the mGluR6 agonist L-APB (5 $\mu \mathrm{m}$ ) and antagonist LY-341495 (7.5 $\mu \mathrm{M}$ ) were perfused onto the retina (left) during and after or (right) after ablation of a cone (dotted lines). $\boldsymbol{C}, \mathbf{D}$, Average dendritic and somatic mGluR6 immunostaining intensities for control (circles) and ablated (triangles) cones under Ames solution (open symbols) and under $5 \mu \mathrm{m} \mathrm{L-APB}$ and $7.5 \mu \mathrm{m} \mathrm{LY}-341495$ ( $\boldsymbol{C}$; closed symbols) or $10 \mu \mathrm{m} \mathrm{L-APB} \mathrm{(} \boldsymbol{D}$; closed symbols) applied (left) during and after or (right) after the ablation of cones. Results from the one-way ANOVA for control (ablated) cones across the Ames solution and antagonist and/or agonist manipulations for the ratio of dendritic to somatic $m G$ luR6 intensities in $C\left[F_{(2,96)}\right.$ $\left.=11.38, p=3.7 \mathrm{e}-5\left(F_{(2,50)}=1.4, p=0.26\right)\right]$ and $\boldsymbol{D}\left[F_{(2,84)}=1.84, p=0.17\left(F_{(2,57)}=0.48, p=0.62\right)\right]$. $\boldsymbol{E}$, Average ratio of dendritic to somatic intensities of mGluR6 immunostaining across the population of type $60 \mathrm{~N}$ cone bipolar cells as a function of the interval between the ablation and fixation for bipolar cells under Ames solution (open black circles) or (left) during and after or (right) after $5 \mu \mathrm{m} \mathrm{L}$-APB and $7.5 \mu \mathrm{m} \mathrm{LY}$-341495 (orange closed circles) or $10 \mu \mathrm{m} \mathrm{L-APB} \mathrm{(blue} \mathrm{closed} \mathrm{circles).} \mathrm{Data} \mathrm{points} \mathrm{represent} \mathrm{mean} \pm$ SEM. Data points under APB fit with a single exponential with the following coefficients: $y 0=0.89 \pm 0.14, A=0.57 \pm 0.16, \tau=50.6 \pm 100$. The time constant for receptor elimination $(\tau)$ is 51 min. Scale bars, $5 \mu \mathrm{m}$.

\section{Loss of homotypic neighboring bipolar cell has no effect on mGluR6 allocation}

Though isolated type $6 \mathrm{ON}$ cone bipolar cells were imaged, these bipolar cells tile the retina in a regular array, and peripheral dendrites tend to share a cone input with a neighboring type $6 \mathrm{ON}$ cone bipolar cell. Do neighboring homotypic bipolar cells also influence receptor allocation? In the Grm6-TdTomato line, neighboring homotypic bipolar cells are occasionally visible (Fig. $7 A$ ). Instead of ablating the presynaptic cone, the neighboring bipolar cell was ablated (Fig. $7 A, B$ ). In this experiment, mGluR6 levels in the dendrites of the remaining bipolar cell was unchanged and fell within the population of control dendritic tips (Fig. 7C). The ratio of dendritic to somatic mGluR6 intensities was not significantly different in the neighbor to the ablated bipolar cell compared with the control cones, suggesting that ablating homotypic neighbors had no noticeable effects on the mGluR6s in the dendrites of the surviving bipolar cell (Fig. 7, statistics). Thus, the major observation of mGluR6 disappearance depends on the contact with the presynaptic cone terminal, not on the static binding of postsynaptic glutamate receptors or on the presence of a homotypic bipolar cell neighbor.

\section{Discussion}

In this study, I introduced an experimental system with fine temporal and spatial control for examining early reactions to damage of presynaptic photoreceptors. Imaging of live and fixed retinae demonstrated what happens to postsynaptic ON cone bipolar cells after the damage of presynaptic cones: mGluR6 disappears from the bipolar cell dendritic tips independent of the later remodeling of dendrites (Strettoi et al., 2003). A subset of ablations showed where and when this process occurs: mGluR6 is lost locally from the bipolar cell dendritic tips where cones were ablated with a time constant of $2 \mathrm{~h}$ following cone ablation. Finally, pharmacological experiments indicate that the mechanism of glutamate receptor loss is independent of mGluR6 occupation, likely suggesting a role for the presynaptic cone in determining proper allocation of postsynaptic mGluR6s.

\section{Receptor plasticity in the retina}

Though models of retinal degeneration have focused on the effects of dendrite sprouting (Haverkamp et al., 2006) and massive circuit rearrangement (Marc et al., 2003), several lines of evidence point to the possibility for receptor alterations as an early 


\section{A}

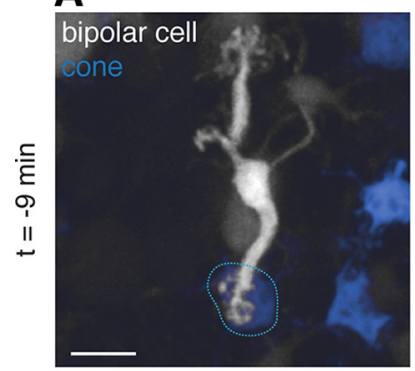

B fixed, $t=132 \mathrm{~min}$
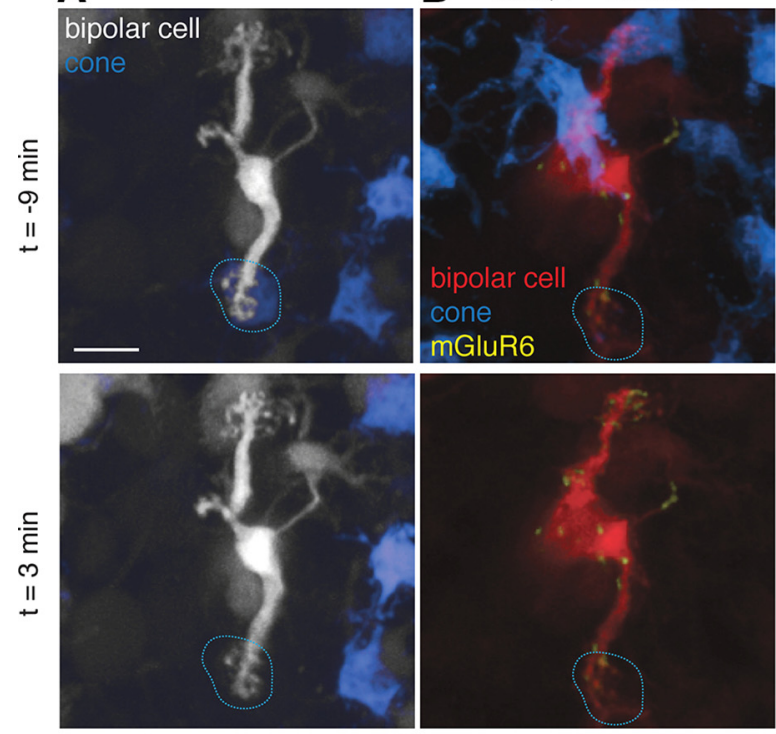

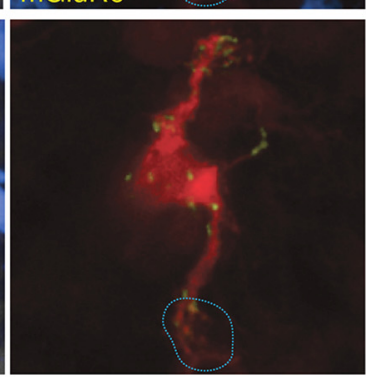

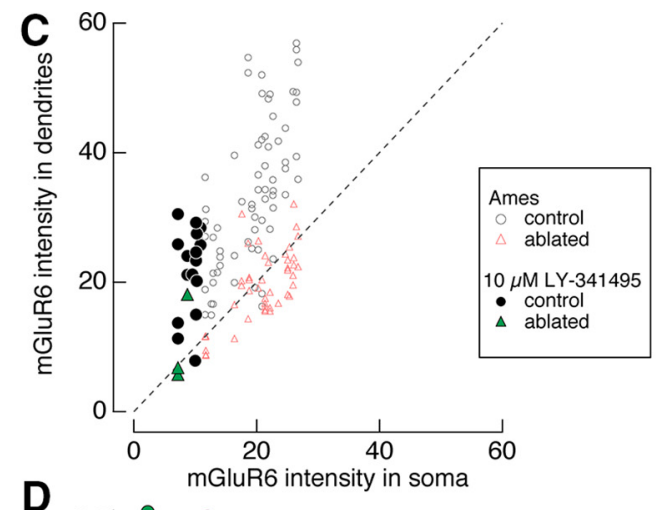

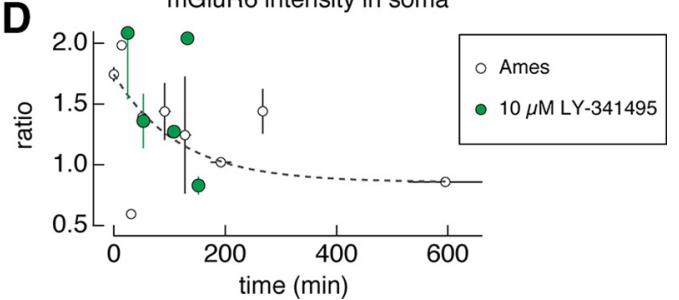

Figure 6. Glutamate receptor antagonist is insufficient to rescue mGluR6. $\boldsymbol{A}, \boldsymbol{B}$, Two-photon images in live retina $(\boldsymbol{A})$ and confocal images in fixed retina $(\boldsymbol{B})$. Type $60 \mathrm{~N}$ cone bipolar cell in which the mGluR6 antagonist LY-341495 (10 $\mu \mathrm{M}$ ) was perfused onto the retina (left) during and after ablation of a cone (dotted line). Time (t) of image acquisition is relative to the time of ablation. $C$,

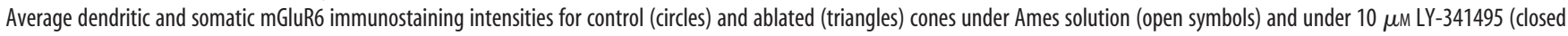
symbols). Results from the one-way ANOVA for control (ablated) cones across the Ames solution and antagonist manipulations for the ratio of dendritic to somatic mGluR6 intensities $\left[F_{(1,81)}=17.5\right.$, $p=7.1 \mathrm{e}-5\left(F_{(1,47)}=2.0, p=0.16\right]$. D, Average ratio of dendritic to somatic intensities of mGluR6 immunostaining across the population of type $60 \mathrm{~N}$ cone bipolar cells as a function of the interval between the ablation and fixation for bipolar cells under Ames solution (open black circles) or $10 \mu \mathrm{m}$ LY-341495 (green closed circles). Data points represent mean \pm SEM. Scale bars, $5 \mu \mathrm{m}$.
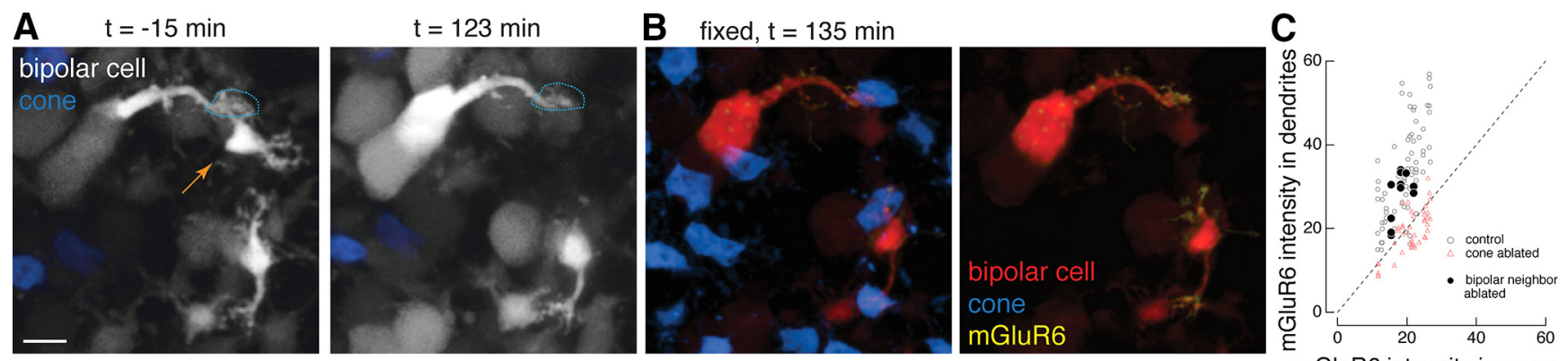

Figure 7. Ablating homotypic neighbors has no effect on mGluR6 localization. $\boldsymbol{A}, \boldsymbol{B}$, Two-photon images of live retina $(\boldsymbol{A})$ and confocal images of fixed retina $(\boldsymbol{B})$. Three type $60 \mathrm{~N}$ cone bipolar cells in close proximity before and after ablation of the middle bipolar cell (orange arrow). The top two bipolar cells once contacted a common cone (dotted lines), which is revealed only after immunostaining with cone arrestin. Time ( $\mathrm{t}$ ) of image acquisition is relative to the time of ablation. C, Average dendritic and somatic mGluR6 immunostaining intensities for bipolar dendritic tips that remained next to an ablated bipolar cell (closed circles) compared with control conditions (open circles) and with ablated cones (open triangles). Results from the one-way ANOVA for control cones and ablated homotypic bipolar cell neighbors for the ratio of dendritic to somatic mGluR6 intensities $\left(F_{(1,76)}=1.43, p=0.24\right)$. Scale bar, $5 \mu \mathrm{m}$.

response to removing a presynaptic partner. In a model of retinitis pigmentosa, Puthussery et al. (2009) demonstrated that the loss of rod photoreceptors led to decreased function in rod bipolar cells. Eventually, when cones started to die, ON cone bipolar cells decreased in function, but the responses of OFF cone bipolar cells were preserved (Puthussery et al., 2009). Such results suggest that receptor loss occurs in stages and can be cell type specific. In corroborating the evidence for receptor plasticity in specific cell types, dark-rearing mice caused the downregulation of mGluR6 at the tips of $\mathrm{ON}$ cone bipolar cells, but not at those of rod bipolar cells (Dunn et al., 2013). In the early stages of retinal degeneration, where dying photoreceptors are scattered among functioning photoreceptors, shrinking bipolar cell receptive fields are a likely consequence of local mGluR6 loss from bipolar cell dendritic branches. The question remains: while downregulation of mGluR6 has been demonstrated, can upregulation also occur? In other words, is plasticity reversible? In an in vivo model of pho- tocoagulation in the rabbit retina, Sher et al. (2013) showed that gaps in ganglion cell receptive fields caused by photoreceptor damage filled in following 2 months of recovery. Such findings suggest that the remaining postsynaptic bipolar cells make synapses with photoreceptors that migrate into the previously damaged region, thus indicating that glutamate receptors would need to be upregulated to create these new functional synapses.

\section{Synapse disassembly beyond the retina: clues about mechanism}

The mechanisms underlying synapse disassembly in the CNS remain a black box compared with the extensive work that has been done in the peripheral nervous system. Studies of the neuromuscular junction have provided evidence for synapse elimination initiated by postsynaptic partners (Culican et al., 1998; Pun et al., 2002) and presynaptic partners (Eaton et al., 2002). The possibility remains that both presynaptic and postsynaptic mechanisms 
initiate synapse disassembly and can do so autonomously (for review, see Goda and Davis, 2003).

At the cone-to-ON cone bipolar cell synapse, we find clues that this process of synapse disassembly was initiated from the presynaptic side. The pharmacological occupation of mGluR6 by the agonist, antagonist, or both in the bipolar cell dendrites opposite to the ablated cones was insufficient to rescue receptors, suggesting that factors other than binding are necessary for keeping the postsynaptic receptors at the dendritic tips of the cone bipolar cell. These results point to a role for factors other than, or in addition to, neurotransmitter release from the presynaptic cone (e.g., trophic factors, synaptic scaffolds, signaling and adhesion molecules, or synaptic cytoskeleton elements such as actin) that may be disrupted in the laser ablation of the presynaptic membrane (Goda and Davis, 2003). Future experiments will explore the mechanisms underlying disassembly at a critical synapse in the retina where damage causes immediate deficits in vision. Here, examination of a specific and well characterized postsynaptic cell type after controlled ablation of presynaptic partners revealed the early stages of the synapse disassembly process, thereby providing insight into synapse disassembly that may occur elsewhere in the CNS, where such control is not yet accessible in the intact circuit.

\section{References}

Akaaboune M, Culican SM, Turney SG, Lichtman JW (1999) Rapid and reversible effects of activity on acetylcholine receptor density at the neuromuscular junction in vivo. Science 286:503-507. CrossRef Medline

Ala-Laurila P, Greschner M, Chichilnisky EJ, Rieke F (2011) Cone photoreceptor contributions to noise and correlations in the retinal output. Nat Neurosci 14:1309-1316. CrossRef Medline

Al-Shamekh S, Goldberg JL (2014) Retinal repair with induced pluripotent stem cells. Transl Res 163:377-386. CrossRef Medline

Culican SM, Nelson CC, Lichtman JW (1998) Axon withdrawal during synapse elimination at the neuromuscular junction is accompanied by disassembly of the postsynaptic specialization and withdrawal of Schwann cell processes. J Neurosci 18:4953-4965. Medline

Dunn FA, Wong RO (2012) Diverse strategies engaged in establishing stereotypic wiring patterns among neurons sharing a common input at the visual system's first synapse. J Neurosci 32:10306-10317. CrossRef Medline

Dunn FA, Della Santina L, Parker ED, Wong RO (2013) Sensory experience shapes the development of the visual system's first synapse. Neuron 80: 1159-1166. CrossRef Medline

Eaton BA, Fetter RD, Davis GW (2002) Dynactin is necessary for synapse stabilization. Neuron 34:729-741. CrossRef Medline

Fei Y, Hughes TE (2001) Transgenic expression of the jellyfish green fluorescent protein in the cone photoreceptors of the mouse. Vis Neurosci 18:615-623. CrossRef Medline

Goda Y, Davis GW (2003) Mechanisms of synapse assembly and disassembly. Neuron 40:243-264. CrossRef Medline

Haverkamp S, Michalakis S, Claes E, Seeliger MW, Humphries P, Biel M, Feigenspan A (2006) Synaptic plasticity in CNGA3(-l-) mice: cone bipolar cells react on the missing cone input and form ectopic synapses with rods. J Neurosci 26:5248-5255. CrossRef Medline

Kerschensteiner D, Morgan JL, Parker ED, Lewis RM, Wong RO (2009) Neurotransmission selectively regulates synapse formation in parallel circuits in vivo. Nature 460:1016-1020. CrossRef Medline

Marc RE, Jones BW, Watt CB, Strettoi E (2003) Neural remodeling in retinal degeneration. Prog Retin Eye Res 22:607-655. CrossRef Medline

Masland RH (2012) The neuronal organization of the retina. Neuron 76: 266-280. CrossRef Medline

Morgans CW, Ren G, Akileswaran L (2006) Localization of nyctalopin in the mammalian retina. Eur J Neurosci 23:1163-1171. CrossRef Medline

Nikonov SS, Brown BM, Davis JA, Zuniga FI, Bragin A, Pugh EN Jr, Craft CM (2008) Mouse cones require an arrestin for normal inactivation of phototransduction. Neuron 59:462-474. CrossRef Medline

Pun S, Sigrist M, Santos AF, Ruegg MA, Sanes JR, Jessell TM, Arber S, Caroni $P$ (2002) An intrinsic distinction in neuromuscular junction assembly and maintenance in different skeletal muscles. Neuron 34:357-370. CrossRef Medline

Puthussery T, Gayet-Primo J, Pandey S, Duvoisin RM, Taylor WR (2009) Differential loss and preservation of glutamate receptor function in bipolar cells in the rd10 mouse model of retinitis pigmentosa. Eur J Neurosci 29:1533-1542. CrossRef Medline

Sher A, Jones BW, Huie P, Paulus YM, Lavinsky D, Leung LS, Nomoto H, Beier C, Marc RE, Palanker D (2013) Restoration of retinal structure and function after selective photocoagulation. J Neurosci 33:6800-6808. CrossRef Medline

Strettoi E, Pignatelli V, Rossi C, Porciatti V, Falsini B (2003) Remodeling of second-order neurons in the retina of $\mathrm{rd} / \mathrm{rd}$ mutant mice. Vision Res 43:867-877. CrossRef Medline

Walsh MK, Lichtman JW (2003) In vivo time-lapse imaging of synaptic takeover associated with naturally occurring synapse elimination. Neuron 37:67-73. CrossRef Medline

Wässle H, Puller C, Müller F, Haverkamp S (2009) Cone contacts, mosaics, and territories of bipolar cells in the mouse retina. J Neurosci 29:106-117. CrossRef Medline 